\title{
ORIGINAL
}

\section{Vasopressin receptor antagonist in the treatment of the syndrome of inappropriate antidiuretic hormone in general hospital practice}

\author{
Rajesh Rajendran ${ }^{1)}$, Ashley B. Grossman ${ }^{2)}$ and Partha Kar ${ }^{1)}$ \\ 1) Department of Diabetes and Endocrinology, Queen Alexandra Hospital, Portsmouth PO6 3LY, United Kingdom \\ 2) Oxford Centre for Diabetes, Endocrinology and Metabolism, University of Oxford, Churchill Hospital, Headington OX3 7LJ, \\ United Kingdom
}

\begin{abstract}
Hyponatraemia (serum sodium concentration $<135 \mathrm{mmol} / \mathrm{L}$ ) is the most common electrolyte disorder in hospitalised patients. We analysed the safety and efficacy of tolvaptan in the treatment of hyponatraemia in hospitalised inpatients and report the first consecutive retrospective clinical case series report based on a single centre experience from the United Kingdom. We sought out the case records of all patients treated with tolvaptan for hyponatraemia over a period of 19 months; 15 episodes of treatment with tolvaptan in 14 patients were analysed. There were 8 women and 6 men (age $72 \pm 16$, (mean \pm standard deviation), range 36 to 90 years, mean BMI $24.9 \pm 8.67,13.9$ to $46.4 \mathrm{~kg} / \mathrm{m}^{2}$ ). Thirteen patients were diagnosed with euvolaemic hyponatraemia. One patient had hypovolaemic hyponatraemia. The median duration of tolvaptan therapy was 3 days ( 1 to 21 days). A serum sodium level of $130 \mathrm{mmol} / \mathrm{L}$ was targeted during therapy and fluid restriction was discontinued. There was a significant change in sodium level from baseline (mean sodium 120.1 $\pm 4.6,108$ $126 \mathrm{mmol} / \mathrm{L}$ ) to cessation of tolvaptan therapy (mean sodium $131.9 \pm 3.6,125-139 \mathrm{mmol} / \mathrm{L}, P<0.0001$ ). The maximum rate of change of sodium was observed in the first 24 hours of therapy (mean $6.7 \pm 2.8,1$ to $11 \mathrm{mmol} / \mathrm{L}$ ) with no patient exceeding $12 \mathrm{mmol} / \mathrm{L}$ in 24 hours and $18 \mathrm{mmol} / \mathrm{L}$ in 48 hours at any point whilst on tolvaptan. No patient developed the osmotic demyelination syndrome. Tolvaptan appears to be safe and effective in the management of hospitalised inpatients with definitive euvolaemic hyponatraemia when close monitoring is observed.
\end{abstract}

Key words: Tolvaptan, Hyponatraemia, Syndrome of inappropriate antidiuretic hormone (SIADH), Vasopressin receptor antagonist, Euvolaemia

HYPONATRAEMIA (defined as a serum sodium $<135 \mathrm{mmol} / \mathrm{L}$ ) is the most common biochemical abnormality seen in hospitalised patients [1], occurring in $15 \%$ to $30 \%$ of such patients $[1,2]$ and in nearly $7 \%$ of ambulatory patients [3]. Severe hyponatraemia (serum sodium $<125 \mathrm{mmol} / \mathrm{L}$ ) is associated with an in-hospital mortality of between $23 \%$ and $50 \%$, depending on the serum sodium concentration at presentation [4], and with increased mortality extending to 6 months of follow-up [5]. The length of hospital stay was also significantly prolonged in hyponatraemic patients [4]. Waikar et al. prospectively studied 98,411 patients with outcomes measured up to 5 years after hospital discharge, and found that even mild hyponatraemia (serum sodium

Submitted May 2, 2012; Accepted Jun. 10, 2012 as EJ12-0171 Released online in J-STAGE as advance publication Jun. 30, 2012 Correspondence to: Rajesh Rajendran, Department of Diabetes and Endocrinology, Queen Alexandra Hospital, Portsmouth PO6 3LY, United Kingdom. E-Mail: rajeshmarthar@yahoo.com
$<135 \mathrm{mmol} / \mathrm{L}$ ) independently predicted mortality [1]. Though traditionally only severe hyponatraemia (serum sodium $<125 \mathrm{mmol} / \mathrm{L}$ ) was considered to be symptomatic and requiring treatment [6], it has been shown that even mild hyponatraemia is associated with attention deficits, falls and unsteadiness, and that these can be improved with correction of hyponatraemia [7]; hyponatraemia may also predispose to an increased risk of fractures in the ambulatory elderly [8].

The syndrome of inappropriate antidiuretic hormone (SIADH) is a common cause of hyponatraemia [9], although most cases of hyponatraemia are associated with hypovolaemia and diuretic use. Non-suppressible relatively higher levels of arginine vasopressin (antidiuretic hormone (ADH), arginine vasopressin (AVP)) are associated with the pathogenesis of hyponatraemia in euvolaemic patients (SIADH), as vasopressin acts on the V2 receptor in the kidney allowing water to be reabsorbed [10] with consequential free water retention; a 
subsequent fall in serum osmolality and serum sodium occur in this situation. The traditional therapy for the condition has been fluid restriction, but this may be unpleasant for the patient and is often difficult to ensure on non-specialist wards. Recently, several AVP receptor antagonists have been developed, and it has been suggested that they may become the mainstay of treatment of SIADH as these agents predictably cause an aquaresis leading to increased serum sodium in the majority of patients with SIADH [11]. The possibility of rapid correction has been of significant concern in all of the AVP receptor antagonist clinical trials [11], but so far osmotic demyelination syndrome has not been reported with any of these agents. There has also been concern that these agents may be inappropriately used in hypovolaemic patients when the AVP release is homeostatic, and blockade may be deleterious.

Tolvaptan, an orally active vasopressin V2-receptor antagonist was first reported to be safe and effective in increasing serum sodium in patients with euvolaemic and hypervolaemic hyponatraemia by the study of ascending levels of tolvaptan (SALT) investigators in 2006 $[12,13]$. However, concerns have been expressed over its safety, efficacy and cost effectiveness over conventional treatments in its use in the acute general hospital setting [14]. Tolvaptan has been licensed for treatment of adult patients with hyponatraemia secondary to SIADH in Europe [15], and for the treatment of clinically significant hypervolaemic and euvolaemic hyponatraemia (serum sodium $<125 \mathrm{mmol} / \mathrm{L}$ or less marked hyponatraemia that is symptomatic and has resisted cor- rection with fluid restriction), including patients with heart failure, cirrhosis and SIADH, in the U.S. [16].

Tolvaptan was approved for use in Queen Alexandra Hospital (QAH), Portsmouth, in April 2010, by Portsmouth and South East Area Hampshire Prescribing Committee, and added to the formulary for prescribing by named consultants (endocrinologists) only with maximum treatment duration of 10 days and on condition that it would not be continued on discharge of patients from hospital. QAH is a 904-bedded hospital that provides secondary care to an ethnically and socio-economically diverse population of approximately 600,000 within its catchment area of Portsmouth City and South East Hampshire [17]. Local guidelines were prepared for its usage at QAH (Table 1). The aim of our study was to assess the safety and efficacy of tolvaptan in an acute clinical setting in hospitalised inpatients.

\section{Materials and Methods}

This was a retrospective consecutive clinical case series study. Clinical and laboratory data were extracted for all patients treated with tolvaptan whilst hospitalised at QAH from $28^{\text {th }}$ April 2010 (when tolvaptan was first approved for use in QAH) until $30^{\text {th }}$ November 2011.

All patients prescribed tolvaptan during their admission were recorded on the pharmacy stock control and dispensing system (JAC version 4.43), and 15 patients were identified from their records. It was not possible to trace the case records for one patient. Data on the remaining 14 patients were collected from clinical case

Table 1 Local QAH guideline for use of tolvaptan in the treatment of hyponatraemia in hospitalised patients with SIADH ${ }^{++}$

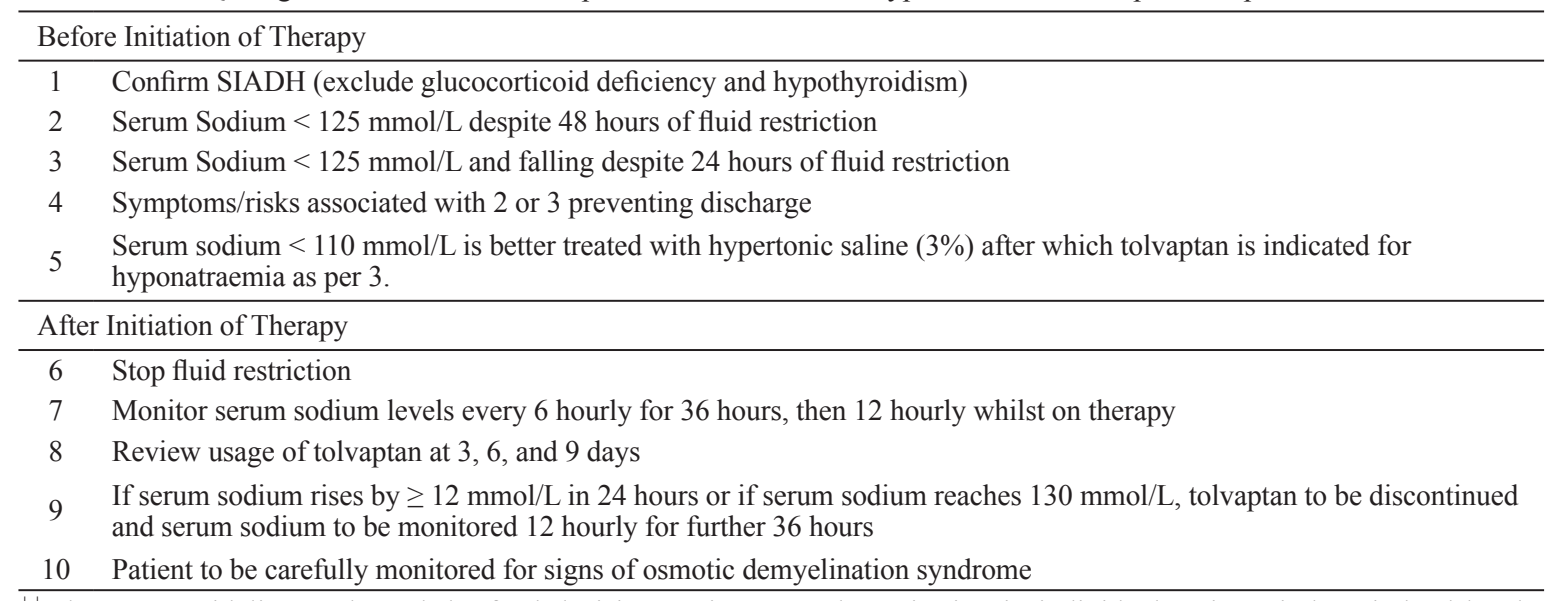

${ }^{++}$These are guidelines only and the final decision on its use and monitoring in individual patients is best judged by the prescribing physician. 
notes, pathology computer systems (iSOFT iLAB Apex and Sunquest ICE), patient observation tracking system (VitalPAC) and patient letters management system. The following data were retrieved and entered on a proforma: demographics, length of hospital stay, diagnosis, co morbidities, in-hospital mortality, location, symptoms on admission, duration of hyponatraemia, treatment given for hyponatraemia prior to commencement of tolvaptan therapy, duration and dose of tolvaptan therapy, and laboratory data including such serum sodium, potassium, calcium, glucose, urea, creatinine, osmolality, $09.00 \mathrm{~h}$ cortisol, T4, TSH, urine osmolality and urine sodium.

This information was entered on an Excel spreadsheet, and results were analysed statistically using Graphpad (www.graphpad.com). Continuous variables were expressed as means \pm standard deviations or medians with interquartile ranges and tested by the Student's $t$-test or Wilcoxon rank sum test, as appropriate. Categorical variables are described as proportions and compared using the chi-squared test. All $P$ values are two-tailed. We acknowledge the limitations of a retrospective case series study [18] but our data accuracy has been verified across different sources to minimise data collection errors. The study was approved as an audit by the Trust (audit reference number 2018).

\section{Results}

Fourteen patients were treated with tolvaptan. Each episode of treatment was analysed separately. One patient was treated twice, on successive admissions. Thus, there were 15 episodes of treatment in 14 patients. Tables 2 and 3 summarises the characteristics of each episode of treatment.

There were 8 women and 6 men (mean age $72 \pm 16$ (mean \pm standard deviation), range 36 to 90 years) with a mean BMI of $24.9 \pm 8.67,13.9$ to $46.4 \mathrm{~kg} / \mathrm{m}^{2}$. On admission to hospital, hyponatraemia was present in all 15 episodes, whilst severe hyponatraemia [4] (serum sodium $<125 \mathrm{mmol} / \mathrm{L}$ ) was present in $12 / 15$ episodes $(80 \%)$. The duration of hyponatraemia [19] was unknown in 8 episodes, acute ( $\leq 48$ hours) in 3 episodes and chronic ( $>48$ hours) in 4 episodes. On review all 15 episodes were associated with confusion at the point of admission, although this was initially attributed to hyponatraemia in only 8 episodes [6]. Irritability, mood change and falls were recorded in 11 of the 15 episodes. Sepsis was present in 6 episodes on admission.

Hyponatraemic patients were diagnosed as having syndrome of inappropriate anti-diuretic hormone (SIADH) based on their clinical volume status, serum osmolalities, urine sodium and osmolalities [19]. All patients had a normal $09.00 \mathrm{~h}$ serum cortisol, T4 and TSH during all the episodes. One patient developed acute severe very hyponatraemia (serum sodium $<120$ $\mathrm{mmol} / \mathrm{L}$ ) following vigorous large volume fluid resuscitation for acute renal impairment. The remaining 13 patients were diagnosed with SIADH prior to 14 episodes of treatment with tolvaptan. The mean length of stay for the 14 episodes (excluding one episode where the patient died as an inpatient on the $27^{\text {th }}$ day of admission) was $25.4 \pm 12.3$ (12-48 days).

The initial therapy for 12 episodes was fluid restriction [19] to 1 litre (mean duration $5.9 \pm 3.1,2-12$ days) prior to commencement of tolvaptan. Demeclocycline [19] was used in two episodes in conjunction with fluid restriction, and once without any fluid restriction, prior to tolvaptan therapy. One patient had been treated with $100 \mathrm{~mL}$ of $3 \%$ hypertonic saline infusion [19] once, 3 days prior to tolvaptan therapy.

Tolvaptan was initiated when conventional methods were considered to be ineffective. A serum sodium level of $130 \mathrm{mmol} / \mathrm{L}$ was targeted during therapy according to locally agreed guidelines (Table 1); fluid restriction was discontinued [12] when tolvaptan therapy was commenced. The median duration of tolvaptan therapy in the 15 episodes was 3 days ( 1 to 21 days): $15 \mathrm{mg}$ of tolvaptan was used in 14 episodes with no dose changes, while $30 \mathrm{mg}$ of tolvaptan was used in one episode in a patient who had previously been treated with $15 \mathrm{mg}$ of tolvaptan and was readmitted with hyponatraemia. Only a single patient, who was treated with $15 \mathrm{mg}$ of tolvaptan for 3 days in the intensive care unit for acute severe hyponatraemia following large volume fluid resuscitation to apparent clinical euvolaemia but with no evidence of inappropriate natriuresis, complained of thirst during therapy [15]. No patient developed osmotic demyelination syndrome [20] as a consequence of hyponatraemia treatment in our study.

There was a significant rise in serum sodium level before (mean sodium $120.1 \pm 4.6,108-126 \mathrm{mmol} / \mathrm{L}$ ) and after (mean sodium $131.9 \pm 3.6,125-139 \mathrm{mmol} / \mathrm{L}$, $P<0.0001)$ tolvaptan therapy. The maximum rate of change of sodium was observed in the first 24 hours of therapy (mean $6.7 \pm 2.8,1-11 \mathrm{mmol} / \mathrm{L}$ ), with 2 patients requiring just one dose of $15 \mathrm{mg}$ of tolvaptan to achieve a target sodium of $\geq 130 \mathrm{mmol} / \mathrm{L}$. In the first 48 hours of therapy, the rate of change of sodium was $9.6 \pm 3.4$, 
Table 2 Summary of patient characteristics during all 15 episodes

\begin{tabular}{|c|c|c|c|c|c|c|c|c|c|c|c|c|c|}
\hline $\begin{array}{l}\text { Episode } \\
\text { of } \\
\text { tolvaptan } \\
\text { use }\end{array}$ & $\begin{array}{c}\text { Age } \\
\text { (years) }\end{array}$ & Sex & $\begin{array}{l}\text { BMI on } \\
\text { admission } \\
\left(\mathrm{kg} / \mathrm{m}^{2}\right)\end{array}$ & $\begin{array}{c}\text { Clinical fluid } \\
\text { status as assessed } \\
\text { by documenting } \\
\text { physician }\end{array}$ & $\begin{array}{c}\text { Serum } \\
\text { osmolality } \\
(285-295 \\
\mathrm{mos} / \mathrm{kg})\end{array}$ & $\begin{array}{l}\text { Urine } \\
\text { osmolality } \\
(\mathrm{mos} / \mathrm{kg})\end{array}$ & $\begin{array}{c}\text { Serum } \\
\text { sodium } \\
(135-146 \\
\mathrm{mmol} / \mathrm{L})\end{array}$ & $\begin{array}{c}\text { Urine } \\
\text { sodium } \\
(\mathrm{mmol} / \mathrm{L})\end{array}$ & $\begin{array}{c}\text { Physician } \\
\text { diagnosis } \\
\text { of } \\
\text { SIADH }\end{array}$ & $\begin{array}{l}\text { Cause } \\
\text { for } \\
\text { SIADH }^{\ddagger}\end{array}$ & $\begin{array}{c}\text { Duration of } \\
\text { hyponatraemia }\end{array}$ & $\begin{array}{l}\text { Treatment given for } \\
\text { hyponatraemia } \\
\text { prior to tolvaptan }\end{array}$ & $\begin{array}{l}\text { Total length } \\
\text { of stay in our } \\
\text { hospital (days) }\end{array}$ \\
\hline 1 & 79 & $\mathrm{~F}$ & 39.8 & Euvolaemic & 240 & 252 & 117 & 35 & Yes & $\begin{array}{l}\text { Lung } \\
\text { cancer }\end{array}$ & Chronic & $\begin{array}{l}\text { FR- } 1 \text { litre for } 3 \text { days } \\
\text { DC- } 14 \text { days }\end{array}$ & 13 \\
\hline 2 & 90 & $\mathrm{~F}$ & 25.9 & Euvolaemic & 241 & 480 & 119 & 106 & Yes & Unknown & Unknown & FR- 1 litre for 2 days & 13 \\
\hline 3 & 47 & $\mathrm{~F}$ & 19.5 & Euvolaemic & 262 & 219 & 122 & 30 & Yes & $\begin{array}{l}\text { Neuro- } \\
\text { sarcoidosis }\end{array}$ & Chronic & FR-1 litre for 3 days & 23 \\
\hline 4 & 84 & M & 46.4 & Euvolaemic & 245 & 520 & 118 & 158 & Yes & Unknown & Acute & FR- 1 litre for 9 days & 48 \\
\hline 5 & 73 & $\mathrm{~F}$ & 21.3 & Euvolaemic & 216 & 345 & 100 & 100 & Yes & Unknown & Unknown & $\begin{array}{c}\text { FR- } 1 \text { litre for } 4 \text { days } \\
3 \% \mathrm{HS}-100 \mathrm{ml}\end{array}$ & 32 \\
\hline 6 & 70 & M & 22.9 & Euvolaemic & 258 & 318 & 123 & 97 & Yes & Unknown & Unknown & FR- 1 litre for 4 days & 33 \\
\hline 7 & 73 & M & 25.6 & Euvolaemic & 252 & 872 & 121 & 32 & Yes & $\begin{array}{l}\text { Lung } \\
\text { cancer }\end{array}$ & Unknown & $\begin{array}{l}\text { FR- } 1 \text { litre for } 10 \text { days } \\
\text { FR- } 750 \mathrm{ml} \text { for } 7 \text { days }\end{array}$ & $27^{\circ}$ \\
\hline 8 & 84 & M & 23.1 & Euvolaemic & 256 & 515 & 116 & 58 & Yes & $\begin{array}{l}\text { Lung } \\
\text { cancer }\end{array}$ & Unknown & $\begin{array}{l}\text { FR- } 1 \text { litre for } 5 \text { days } \\
\text { FR- } 750 \mathrm{ml} \text { for } 5 \text { days }\end{array}$ & 12 \\
\hline $9^{\#}$ & 52 & $\mathrm{~F}$ & 21.8 & $\begin{array}{l}\text { Hypovolaemic / } \\
\text { Euvolaemic }\end{array}$ & 258 & 271 & 115 & $<10$ & No & $\begin{array}{c}\text { Not } \\
\text { applicable }\end{array}$ & Acute & Not applicable & 45 \\
\hline 10 & 36 & $\mathrm{~F}$ & 29.6 & Euvolaemic & 258 & 259 & 122 & 46 & Yes & Unknown & Acute & FR- 1 litre for 7 days & 29 \\
\hline 11 & 82 & $\mathrm{~F}$ & 20.6 & Euvolaemic & 248 & 227 & 116 & 36 & Yes & Unknown & Unknown & None & 12 \\
\hline 12 & 88 & $\mathrm{~F}$ & 18.1 & Euvolaemic & 258 & 135 & 126 & 22 & Yes & Unknown & Unknown & $\begin{array}{c}\text { FR- } 1 \text { litre for } 5 \text { days } \\
\text { FR- } 750 \mathrm{ml} \text { for } 5 \text { days } \\
\text { DC- } 7 \text { days }\end{array}$ & 29 \\
\hline 13 & 74 & M & 13.9 & Euvolaemic & 233 & 361 & 110 & 55 & Yes & Unknown & Unknown & FR- 1 litre for 12 days & 19 \\
\hline $14 *$ & 74 & M & 19.9 & Euvolaemic & 265 & 401 & 125 & 25 & Yes & Unknown & Chronic & FR- 1 litre for 7 days & 13 \\
\hline $15^{*}$ & 74 & M & 19.9 & Euvolaemic & 252 & 373 & 121 & 82 & Yes & Unknown & Chronic & DC- 10 days & 34 \\
\hline
\end{tabular}

*Episodes 14, 15 occurred in the same patient during successive admissions, ${ }^{\#}$ Patient was admitted with sepsis and sodium level of $125 \mathrm{mmol} / \mathrm{L}$, following which she developed acute renal failure. She was volume resuscitated to apparent clinical euvolaemia with 3 litres of intravenous normal saline and 3 litres of Hartmann's solution in 24 hours, but she developed acute very severe hyponatraemia. Tolvaptan was used in her with careful monitoring of her electrolytes every 3 hours on intensive care unit, ${ }^{\$}$ Syndrome of inappropriate anti-diuretic hormone [19], ${ }^{\S}$ Duration of hyponatraemia [19] - Acute: $\leq 48$ hours, Chronic: $>48$ hours, ${ }^{\circ}$ Patient died whilst in hospital, ${ }^{\dagger}$ Treatment for hyponatraemia prior to tolvaptan therapy [19]: FR- Fluid restriction, DC- Demeclocycline, $3 \%$ HS- Hypertonic saline

range $4-17 \mathrm{mmol} / \mathrm{L}$. In no patient did the rate of change in serum sodium rise exceed $12 \mathrm{mmol} / \mathrm{L}$ in 24 hours and/ or $18 \mathrm{mmol} / \mathrm{L}$ in 48 hours at any point whilst on tolvaptan, a rate of change above which osmotic demyelination syndrome has been reported [20]. There were small insignificant rises in serum potassium (mean potassium $4.45 \pm$ $0.64,3.6-5.8 \mathrm{mmol} / \mathrm{L}$ prior to commencement of tolvaptan therapy, $4.5 \pm 0.62,3.6-5.6 \mathrm{mmol} / \mathrm{L}$ at the end of tolvap- $\tan$ therapy, $P>0.05$ ), serum urea (mean urea $6.2 \pm 4.1,2.8$ $18.3 \mathrm{mmol} / \mathrm{L}$ prior to commencement of tolvaptan therapy and 7.2 $\pm 3.4,1.4-15.6 \mathrm{mmol} / \mathrm{L}$ at end of tolvaptan therapy, $P>0.05$ ), and serum creatinine (mean creatinine $104 \pm 73$, 38-335 umol/L prior to commencement of tolvaptan therapy and $109 \pm 82,42-382 \mathrm{umol} / \mathrm{L}$ at end of tolvaptan therapy, $P>0.05$ ). Local guidelines (Table 1) were followed for initiation and monitoring of tolvaptan therapy. 
Table 3 Summary of change in serum electrolytes during all 15 episodes

\begin{tabular}{|c|c|c|c|c|c|c|c|c|c|c|c|c|c|}
\hline \multirow{2}{*}{$\begin{array}{l}\text { Episode of } \\
\text { tolvaptan } \\
\text { use }\end{array}$} & \multirow{2}{*}{$\begin{array}{c}\text { Sodium } \\
\text { level on } \\
\text { admission } \\
(135-146 \\
\mathrm{mmol} / \mathrm{L})\end{array}$} & \multicolumn{4}{|c|}{$\begin{array}{l}\text { Baseline electrolytes immediately prior to } \\
\text { tolvaptan therapy }\end{array}$} & \multicolumn{4}{|c|}{ Electrolytes at end of tolvaptan therapy } & \multicolumn{2}{|c|}{$\begin{array}{l}\text { Rate of change }{ }^{+} \text {of sodium } \\
(\mathrm{mmol} / \mathrm{L})\end{array}$} & \multirow{2}{*}{$\begin{array}{l}\text { Total change } \\
\text { in sodium } \\
\text { (mmol/L) } \\
\text { at end of } \\
\text { therapy }\end{array}$} & \multirow{2}{*}{$\begin{array}{l}\text { Total } \\
\text { number } \\
\text { of days of } \\
\text { tolvaptan } \\
\text { usage }\end{array}$} \\
\hline & & $\begin{array}{c}\text { Sodium } \\
(135-146 \\
\mathrm{mmol} / \mathrm{L})\end{array}$ & $\begin{array}{c}\text { Potassium } \\
(3.5-5 \\
\mathrm{mmol} / \mathrm{L})\end{array}$ & $\begin{array}{c}\text { Urea } \\
(2.9-7.1 \\
\mathrm{mmol} / \mathrm{L})\end{array}$ & $\begin{array}{c}\text { Creatinine } \\
(60-110 \\
\text { umol/L) }\end{array}$ & $\begin{array}{c}\text { Sodium } \\
(135-146 \\
\mathrm{mmol} / \mathrm{L})\end{array}$ & $\begin{array}{l}\text { Potassium } \\
(3.5-5 \\
\mathrm{mmol} / \mathrm{L})\end{array}$ & $\begin{array}{c}\text { Urea } \\
(2.9-7.1 \\
\mathrm{mmol} / \mathrm{L})\end{array}$ & $\begin{array}{c}\text { Creatinine } \\
(60-110 \\
\text { umol/L) }\end{array}$ & $\begin{array}{l}\text { First } 24 \text { hours } \\
\text { of tolvaptan } \\
\text { therapy }\end{array}$ & $\begin{array}{l}\text { First } 48 \text { hours } \\
\text { of tolvaptan } \\
\text { therapy }\end{array}$ & & \\
\hline 1 & 117 & 121 & 4.6 & 2.8 & 61 & 134 & 4.9 & 4.9 & 75 & 9 & 11 & 13 & 6 \\
\hline 2 & 119 & 108 & 5.4 & 5.2 & 72 & 125 & 5.3 & 6.6 & 71 & 11 & 17 & 17 & 2 \\
\hline 3 & 122 & 122 & 5 & 6.4 & 144 & 126 & 5.6 & 7.7 & 177 & 5 & 4 & 4 & 2 \\
\hline 4 & 118 & 117 & 5.3 & 18.3 & 154 & 134 & 5.1 & 9.1 & 78 & 3 & 9 & 17 & 4 \\
\hline 5 & 100 & 121 & 3.7 & 3.8 & 38 & 133 & 4.6 & 5.1 & 47 & 4 & 8 & 12 & 4 \\
\hline 6 & 123 & 121 & 4.2 & 5.5 & 93 & 131 & 4.5 & 5.9 & 109 & 10 & - & 10 & 1 \\
\hline 7 & 121 & 123 & 4.1 & 6.8 & 74 & 134 & 4 & 9.7 & 85 & 8 & 11 & 11 & 2 \\
\hline 8 & 116 & 123 & 4.6 & 5.1 & 91 & 132 & 5.3 & 6.1 & 97 & 9 & - & 9 & 1 \\
\hline 9 & 125 & 115 & 4.6 & 11.5 & 335 & 128 & 3.7 & 15.6 & 382 & 7 & 13 & 13 & 3 \\
\hline 10 & 122 & 125 & 4.4 & 2.9 & 66 & 139 & 4.5 & 7.5 & 83 & 10 & 12 & 14 & 3 \\
\hline 11 & 116 & 117 & 4.1 & 2.9 & 70 & 133 & 4 & 3.8 & 90 & 6 & 11 & 16 & 7 \\
\hline 12 & 126 & 126 & 3.6 & 2.9 & 54 & 133 & 3.6 & 1.4 & 42 & 1 & 6 & 7 & 3 \\
\hline 13 & 110 & 117 & 5.8 & 9 & 148 & 130 & 4.2 & 11.9 & 127 & 7 & 7 & 13 & 5 \\
\hline $14^{*}$ & 125 & 123 & 3.9 & 5.4 & 85 & 131 & 4 & 5.4 & 93 & 6 & 8 & 8 & 2 \\
\hline $15^{*}$ & 121 & 122 & 4.1 & 5.3 & 70 & 135 & 4.2 & 7.8 & 85 & 5 & 8 & 13 & $21^{\times}$ \\
\hline
\end{tabular}

*Episodes 14,15 occurred in the same patient during different admissions, ${ }^{+}$Rate of change of sodium was calculated as follows: First 24 hours of tolvaptan therapy $=$ Sodium level 24 hours after tolvaptan administration minus baseline sodium value just prior to tolvaptan administration; First 48 hours of tolvaptan therapy $=$ Sodium level 48 hours after tolvaptan therapy minus baseline sodium value just prior to tolvaptan administration, ${ }^{\Delta}$ Total change in sodium levels at end of tolvaptan therapy was calculated as follows: Sodium level 24 hours after last tolvaptan dose minus baseline sodium value just prior to tolvaptan administration, ${ }^{\times}$Only episode where $30 \mathrm{mg}$ of tolvaptan was used with intermittent reduction to $15 \mathrm{mg}$, and used for longer than the agreed 10 days with the prescribing committee

\section{Discussion}

Hyponatraemia is frequently seen in both outpatients and hospitalised patients, and while there have been a number of reviews and classifications $[6,9,11$, $19,21]$, its diagnosis and management are not always straightforward and the key factor remains the clinical assessment of the fluid status of patient [11, 19, 21]. Bartter and Schwartz first described this syndrome in 1957 [22] and while there are differences in the cut-off of natriuresis amongst different reviewers (Hannon et al. [21] - urine sodium $>40 \mathrm{mmol} / \mathrm{L}$, Reynolds et al. [19] - urine sodium $>20 \mathrm{mmol} / \mathrm{L}$, and Verbalis et al. [11] - urine sodium $>30 \mathrm{mmol} / \mathrm{L})$, the other diagnostic criteria remain uncontroversial the demonstration of hypo-osmolality, inappropriate urine concentration for the serum hyponatraemia and clinical euvolaemia with exclusion of hypothyroidism and glucocorticoid deficiency.

The correction of acute and chronic hyponatraemia in SIADH patients can often be challenging and traditionally several strategies such as fluid restriction, demeclo- cyline, lithium, loop diuretics in combination with salt tablets, urea tablets and hypertonic saline (3\%) have been debated and described with no consensus as to the most ideal, safe and effective strategy $[6,9,11,19$, 21]. It is well known that the rapid correction of serum sodium of $\geq 12 \mathrm{mmol} / \mathrm{L}$ in 24 hours and $\geq 18 \mathrm{mmol} / \mathrm{L}$ in 48 hours can potentially lead to dangerous neurological complications [20]. Recently-developed aquaretic therapies such as AVP receptor antagonists have been shown to increase serum sodium in SIADH patients $[11,23]$. Although to date the osmotic demyelination syndrome has not been reported with any of these agents, the possibility of rapid correction has been of significant concern with all the AVP receptor antagonists [11, 14], and the FDA has issued a "black box warning" indicating that therapy with tolvaptan should be initiated in a hospital setting with close monitoring of serum sodium [16].

Verbalis et al. [13] in their subgroup analysis of SIADH patients from the combined SALT population showed similar results to the combined SALT population regarding safety and efficacy of tolvaptan. Of the 110 SIADH patients in the SALT trials randomised to 
tolvaptan and placebo therapy, 42 patients completed the full 30-day treatment period in each group. The mean sodium change from baseline was $2.9 \mathrm{mmol} / \mathrm{L}$ for placebo and $8.5 \mathrm{mmol} / \mathrm{L}$ on day 30 for tolvaptan $(P=0.001)$; $3 / 51$ patients exceeded protocol recommended correction limits of a rise in sodium of $>12 \mathrm{mmol} / \mathrm{L}$ in 24 hours and $>18 \mathrm{mmol} / \mathrm{L}$ in 48 hours, but none developed the osmotic demyelination syndrome.

Gheorghiade et al. [24] studied the effect of tolvaptan versus fluid restriction plus placebo on serum sodium concentration in hospitalised patients with euvolaemic or hypervolaemic hyponatremia, and concluded that tolvaptan appeared to be more effective than fluid restriction in treating hyponatraemia in this setting. There was no subgroup analysis for the 10 SIADH patients out of 28 patients in this study. Vaghasiya et al. [25] studied the effect of a single $15 \mathrm{mg}$ dose of tolvaptan in 13 patients with hyponatraemia, of which 8 patients had SIADH. The mean serum sodium rise was $6.4 \mathrm{mmol} / \mathrm{L}$ in 24 hours. Three patients, all with SIADH, showed a $8 \mathrm{mmol} / \mathrm{L}$ rise in serum sodium within 12 hours, and received small amounts of 5\% Dextrose infusion to attenuate changes in serum sodium. There have also been isolated reports of a single $15 \mathrm{mg}$ dose of tolvaptan causing a rapid rise in serum sodium of $\geq 12 \mathrm{mmol} / \mathrm{L}$ in 24 hours [26, 27], but it was therapeutically targeted in one patient where severe cerebral oedema secondary to hyponatraemia resolved with its correction following tolvaptan therapy [26], whereas in the other patient it caused significant aquaresis leading to symptomatic hypotension [27].

No patient developed rapid correction of sodium or osmotic demyelination syndrome in our study, and they were carefully monitored in keeping with our local protocol. Owing to paucity of data, there is concern for its use in patients with very severe hyponatraemia (serum sodium $<120 \mathrm{mmol} / \mathrm{L}$ ). We had 5 such patients in this cohort where it was safe and effective. Vaptans should not be used for patients with suspected or confirmed hypovolaemic hyponatraemia as it can cause significant aquaresis that can potentially exacerbate the hypovolaemic state and clinical situation despite improve- ment in serum sodium. There was one patient in our cohort where this occurred.

The most likely role for vaptans in the immediate future is the treatment of in-patient hyponatraemia where fluid restriction has failed, or a shorter length of stay in hospital is desired as they seem more effective than fluid restriction $[12,13,24]$. Besides, fluid restriction on a general medical ward is often not easily or correctly implemented and is more unpleasant to the patient, and therefore patient acceptability of vaptans may be superior to fluid restriction. However, the extent to which vaptans will replace fluid restriction as first-line treatment is likely to depend on appropriate drug pricing to permit its use in the already over stretched therapeutic budgets, although if it can be demonstrated that the length of stay is significantly reduced then its acceptability amongst health care providers might increase.

In conclusion, tolvaptan, a selective oral vasopressin V2-receptor antagonist appears to be safe and efficacious in the management of hospitalised inpatients with definite euvolaemic hyponatraemia, when initiated and monitored in the hospital setting under specialist supervision following appropriate guidelines. We recommend that serum electrolytes are carefully monitored in the first 48 hours of treatment initiation and at least daily thereafter until target sodium levels are achieved and tolvaptan stopped before discharge. However, more clinical studies are needed before it could be recommended for routine use in out-patients and long-term therapy for SIADH.

\section{Acknowledgements}

We thank Luke Groves, Lead Pharmacist, for obtaining the list of patients treated with tolvaptan. We also would like to thank our medical records department for obtaining the case records of patients in this study.

\section{Conflict of Interest}

The authors declare no conflict of interest with any of the work presented.

\section{References}

1. Waikar SS, Mount DB, Curhan GC (2009) Mortality after hospitalization with mild, moderate, and severe hyponatremia. Am J Med 122: 857-865.
2. Upadhyay A, Jaber BL, Madias NE (2006) Incidence and prevalence of hyponatremia. Am J Med 119: S30S35. 
3. Hawkins RC (2003) Age and gender as risk factors for hyponatremia and hypernatremia. Clin Chim Acta 337: 169-172.

4. Gill G, Huda B, Boyd A, Skagen K, Wile D, et al. (2006) Characteristics and mortality of severe hyponatraemiaa hospital-based study. Clin Endocrinol (Oxf) 65: 246249.

5. Clayton JA, Le Jeune IR, Hall IP (2006) Severe hyponatremia in medical in-patients: aetiology, assessment and outcome. QJM 99: 505-511.

6. Androgué HJ, Madias NE (2000) Hyponatremia. N Engl J Med 342: 1581-1589.

7. Renneboog B, Musch W, Vandemergel X, Manto MU, Decaux G (2006) Mild chronic hyponatremia is associated with falls, unsteadiness, and attention deficits. Am J Med 119: 71.e1-71.e8.

8. Gankam Kengne F, Andres C, Sattar L, Melot C, Decaux $\mathrm{G}$ (2008) Mild hyponatremia and risk of fracture in the ambulatory elderly. QJM 101: 583-588.

9. Ellison DH, Berl T (2007) The syndrome of inappropriate antidiuresis. $N$ Engl J Med 356: 2064-2072.

10. Ishikawa S, Schrier RW (2003) Pathophysiological roles of arginine vasopressin and aquaporin-2 in impaired water secretion. Clin Endocrinol (Oxf) 58: 1-17.

11. Verbalis JG, Goldsmith SR, Greenberg A, Schrier RW, Sterns TH (2007) Hyponatremia treatment guidelines 2007: Expert panel recommendations. Am J Med 120: S1-S21.

12. Schrier RW, Gross P, Gheorghiade M, Berl T, Verbalis $\mathrm{JG}$, et al. for the SALT investigators (2006) Tolvaptan, a selective oral vasopressin V2-receptor antagonist for hyponatremia. N Eng J Med 355: 2099-2112.

13. Verbalis JG, Adler S, Schrier RW, Berl T, Zhao Q, et al. for the SALT investigators. (2011) Efficacy and safety of oral tolvaptan therapy in patients with the syndrome of inappropriate antidiuretic hormone secretion. Eur $J$ Endocrinol 164: 725-732.

14. Amin A, Meeran K (2010) New drugs for hyponatraemia. BMJ 341: c6219.

15. http://www.samsca.co.uk/prescribing-information.html (last accessed $14^{\text {th }}$ February 2012)

16. http://www.samsca.com/ (last accessed $14^{\text {th }}$ February 2012)

17. www.porthosp.nhs.uk

18. Hess DR (2004) Retrospective studies and chart reviews. Respir Care 49:1171-1174.

19. Reynolds RM, Seckl JR (2005) Hyponatraemia for the clinical endocrinologist. Clin Endocrinol (Oxf) 63:366374.

20. Sterns RH, Cappuccio JD, Silver SM, Cohen EP (1994) Neurologic sequelae after treatment of severe hyponatremia: a multicenter perspective. J Am Soc Nephrol 4:1552-1530.

21. Hannon MJ, Thompson CJ (2010) The syndrome of inappropriate antidiuretic hormone: prevalence, causes and consequences. Eur J Endocrinol 162: S5-S12.

22. Schwartz WB, Bennett W, Curelop S, Bartter FC (1957) A syndrome of renal sodium loss and hyponatremia probably resulting from inappropriate secretion of antidiuretic hormone. Am J Med 23: 529-542.

23. Parashar A, Martinucci P, Panesar M (2007) Vasopressin receptor antagonists. Dial Transplant 36:266-274.

24. Gheorghiade M, Gottlieb SS, Udelson JE, Konstam MA, Czerwiec F, et al. for the tolvaptan investigators (2006) Vasopressin V2 receptor blockade with tolvaptan versus fluid restriction in the treatment of hyponatremia. $\mathrm{Am} \mathrm{J}$ Cardiol 97:1064-1067.

25. Vaghasiya RP, DeVita MV, Michelis MF (2011) Serum and urine responses to the aquaretic agent tolvaptan in hospitalized hyponatremic patients. Int Urol Nephrol 44:865-871.

26. Graziani G, Cucchiari D, Aroldi A, Angelini C, Gaetani P, et al. (2012) Syndrome of inappropriate secretion of antidiuretic hormone in traumatic brain injury: when tolvaptan becomes a life saving drug. J Neurol Neurosurg Psychiatry 83:510-512.

27. Torres AC, Wickham EP, Biskobing DM (2011) Tolvaptan for the management of syndrome of inappropriate antidiuretic hormone secretion: lessons learnt in titration of dose. Endocr Pract 17:e97-100. 